OPEN ACCESS

Check for updates

\section{Association of early postnatal transfer and birth outside a tertiary hospital with mortality and severe brain injury in extremely preterm infants: observational cohort study with propensity score matching}

\author{
Kjell Helenius, ${ }^{1,2,3}$ Nicholas Longford, ${ }^{3}$ Liisa Lehtonen, ${ }^{1,2}$ Neena Modi, ${ }^{3}$ Chris Gale, ${ }^{3}$ \\ on behalf of the Neonatal Data Analysis Unit and the United Kingdom Neonatal Collaborative
}

${ }^{1}$ Department of Paediatrics and Adolescent Medicine, Turku University Hospital, Turku,

Finland

${ }^{2}$ Department of Clinical

Medicine, University of Turku,

Turku, Finland

${ }^{3}$ Section of Neonatal Medicine, Department of Medicine,

Chelsea and Westminster

campus, Imperial College

London, London SW10 9NH, UK

Correspondence to: C Gale

christopher.gale@imperial.ac.uk

(or @DrCGale on Twitter;

ORCID 0000-0002-1089-7945)

Additional material is published online only. To view please visit the journal online.

Cite this as: $B M J$ 2019;367:15678 http://dx.doi.org/10.1136/bmj.l5678

Accepted: 31 August 2019

\section{ABSTRACT}

OBJECTIVE

To determine if postnatal transfer or birth in a nontertiary hospital is associated with adverse outcomes.

DESIGN

Observational cohort study with propensity score matching.

SETTING

National health service neonatal care in England; population data held in the National Neonatal Research Database.

\section{PARTICIPANTS}

Extremely preterm infants born at less than 28 gestational weeks between 2008 and 2015 $(n=17577)$ grouped based on birth hospital and transfer within 48 hours of birth: upward transfer (non-tertiary to tertiary hospital, $n=2158$ ), non-tertiary care (born in non-tertiary hospital; not transferred, $n=2668$ ), and controls (born in tertiary hospital; not transferred, $n=10866$ ). Infants were matched on propensity scores and predefined background variables to form subgroups with near identical distributions of confounders. Infants transferred between tertiary hospitals (horizontal transfer) were separately matched to controls in a 1:5 ratio.

\section{MAIN OUTCOME MEASURES}

Death, severe brain injury, and survival without severe brain injury.

RESULTS

2181 infants, 727 from each group (upward transfer, non-tertiary care, and control) were well matched. Compared with controls, infants in the upward transfer group had no significant difference in the

\section{WHAT IS ALREADY KNOWN ON THIS TOPIC}

Early postnatal transfer of extremely preterm infants between hospitals increased in England after the introduction of a networked model of neonatal care

In the context of modern care and specialised transfer teams, the association between early postnatal transfers and neonatal outcomes is not known

\section{WHAT THIS STUDY ADDS}

In extremely preterm infants, birth in a non-tertiary hospital is associated with an increased risk of death, and transfer in the first 48 hours is associated with an increased risk of severe brain injury, compared with infants born in hospitals with tertiary neonatal care who are not transferred in the first 48 hours odds of death before discharge (odds ratio 1.22, $95 \%$ confidence interval 0.92 to 1.61 ) but significantly higher odds of severe brain injury $(2.32,1.78$ to 3.06 ; number needed to treat (NNT) 8) and significantly lower odds of survival without severe brain injury $(0.60,0.47$ to 0.76 ; NNT 9). Compared with controls, infants in the non-tertiary care group had significantly higher odds of death $(1.34,1.02$ to 1.77 ; NNT 20) but no significant difference in the odds of severe brain injury $(0.95,0.70$ to 1.30$)$ or survival without severe brain injury (0.82, 0.64 to 1.05$)$. Compared with infants in the upward transfer group, infants in the non-tertiary care group had no significant difference in death before discharge $(1.10,0.84$ to 1.44$)$ but significantly lower odds of severe brain injury $(0.41$, 0.31 to 0.53 ; NNT 8) and significantly higher odds of survival without severe brain injury $(1.37,1.09$ to 1.73; NNT 14). No significant differences were found in outcomes between the horizontal transfer group $(n=305)$ and controls $(n=1525)$.

\section{CONCLUSIONS}

In extremely preterm infants, birth in a non-tertiary hospital and transfer within 48 hours are associated with poor outcomes when compared with birth in a tertiary setting. We recommend perinatal services promote pathways that facilitate delivery of extremely preterm infants in tertiary hospitals in preference to postnatal transfer.

\section{Introduction}

About one in 20 preterm infants in high income countries are born at less than 28 weeks' gestation (5.7\% in the United Kingdom and $7 \%$ in the United States) ${ }^{1}{ }^{2}$; these extremely preterm infants are at high risk of death and neonatal morbidity, such as periventricular and intraventricular haemorrhage $\mathrm{e}^{3}$ and long term disability. ${ }^{5} 6$ Caring for extremely preterm infants is complex, and previous studies have shown optimal outcomes when care is provided in tertiary hospitals. ${ }^{7-11}$ Such hospitals have a delivery unit equipped and staffed to provide a full range of perinatal and obstetric care for mothers, and a neonatal intensive care unit in which extremely preterm infants can be stabilised and receive ongoing care. Several national guidelines recommend a regionalised model of care for extremely preterm infants, where the goal is to deliver these infants in tertiary hospitals. ${ }^{12-14}$

When women at risk of extremely preterm delivery present at non-tertiary hospitals, transfer to a tertiary hospital can occur either before delivery (prenatal or in 
utero transfer) or after delivery following stabilisation of the infant in the non-tertiary hospital (postnatal transfer). In England, postnatal transfers increased after the reorganisation of care into regional networks in 2007. ${ }^{15} 16$ During 2009-10 less than 50\% of infants born at 27 and 28 weeks' gestation in England were delivered in high volume ( $>2000$ annual neonatal intensive care days) hospitals, whereas reports from New South Wales, Australia, and Finland showed that $85 \%$ and $95 \%$, respectively, of infants born at less than 28 weeks' gestation were delivered in tertiary hospitals. ${ }^{17-19}$ Although historical studies show that preterm infants who underwent postnatal transfer had higher rates of adverse outcomes than infants born in tertiary hospitals, ${ }^{20-22}$ recent studies have shown equivocal results on the association between early postnatal transfer and outcomes. ${ }^{23-27}$ It is unclear whether the association between postnatal transfer and adverse outcomes persists in the context of modern neonatal care and dedicated neonatal transfer services. Harms associated with postnatal transfer might relate to suboptimal stabilisation at a non-tertiary hospital, the transfer of sicker infants, or the transfer itself. This is relevant to the organisation of perinatal health services because early postnatal transfers are increasingly common in the UK and other high income countries following the introduction of highly specialised neonatal transfer services. ${ }^{15} 28$

We examined the association between outcomes and early postnatal transfer and ongoing non-tertiary neonatal care in extremely preterm infants born in England. We also sought to separate the possible effects of postnatal transfer from those of delivery and initial stabilisation in a non-tertiary hospital. Because these research questions are not amenable to a randomised controlled trial, we conducted an observational study applying propensity score matching to form groups for comparison with near identical distributions of background and potential confounder variables. Our hypothesis was that mortality and severe brain injury would be higher in transferred infants compared with non-transferred infants born in tertiary hospitals.

\section{Methods}

We performed a retrospective cohort study of all infants born before 28 weeks' gestation and admitted to neonatal units in England from 1 January 2008 to 31 December 2015. Data were extracted from the UK National Neonatal Research Database (NNRD), which holds deidentified descriptive (eg, birth weight), daily (eg, daily respiratory support), episodic (eg, surgery), and diagnostic data extracted from routine electronic health records for all infants admitted to national health service neonatal units in England from 2012 to present, and most infants from 2008 to 2011. In England, neonatal care for extremely preterm infants is not provided outside the NHS. Data are cleaned before inclusion in the NNRD; records with implausible data configurations are queried and, if necessary, corrected by the treating clinicians. A formal comparison of NNRD data with case record forms from a multicentre, randomised controlled trial ${ }^{29}$ showed high data agreement and a high coverage of infants included in the NNRD compared with national statistics; for infants born at 25 gestational weeks or more the NNRD covers close to $100 \%$ of national live births and about $70 \%$ and $90 \%$ of infants born at 23 and 24 gestational weeks, respectively. The NNRD contains a clinical dataset (the National Neonatal Data Set), which is an approved NHS information standard for England and contained within the NHS Data Dictionary (see data items at www.datadictionary.nhs.uk/data_dictionary/ messages/clinical_data_sets/data_sets/national_ neonatal_data_set/national_neonatal_data_set_-episodic_and_daily_care_fr.asp?shownav $=1$. . $^{30}$

English neonatal units are organised in regional networks of non-tertiary and tertiary neonatal units. The intention is for infants requiring high level care to receive it in a tertiary neonatal unit, with step-down transfer to a non-tertiary neonatal unit within the same network when appropriate. Neonatal units in English hospitals are classified as special care baby units, local neonatal units, and neonatal intensive care units $^{31}$; in this study neonatal intensive care units are referred to as tertiary neonatal units. These definitions differ slightly from those of the American Academy of Paediatrics. Local neonatal units in the UK are generally expected to be able to care for uncomplicated, singleton infants from 27 weeks' gestation onwards and twins or higher order multiples from 28 weeks' gestation onwards and to arrange in utero transfer when delivery is expected at lower gestational ages or postnatal transfer after delivery of an infant at a lower gestational age. Variation exists within England, however, and many networks apply a gestational age of 28 weeks as the threshold for referral from a hospital with a local neonatal unit to one with a tertiary neonatal unit. Special care baby units are expected to be able to care for uncomplicated, singleton infants of 32 weeks' gestation onwards and to transfer infants at lower gestational ages. One aim of this organisational framework is to deliver extremely preterm infants at hospitals with tertiary neonatal units. Since the introduction of a networked model of neonatal care, however, postnatal transfers in England have become more frequent. ${ }^{15}$ Dispatching resuscitation teams to assist at the delivery of extremely preterm deliveries is not standard practice in England.

We defined four groups of infants based on birth hospital and transfer status at 48 hours, selected a priori based on previous work. ${ }^{15} 25$ The upward transfer group comprised infants born in a hospital with a local neonatal unit and transferred to a tertiary hospital within 48 hours. The non-tertiary care group comprised infants born in a hospital with a local neonatal unit and not transferred within 48 hours; this group was not prespecified in the protocol and analysis was undertaken when it became apparent that many infants were defined as belonging within this group. The horizontal transfer group comprised infants born in a tertiary hospital and transferred within 48 hours to a different tertiary hospital for non-clinical reasons 
such as insufficient capacity. The control group comprised infants born in a tertiary hospital and not transferred within 48 hours.

For the primaryanalysis weidentified matched groups of infants from non-tertiary care, upward transfer, and control. Comparisons undertaken between these three matched groups took place between infants in the upward transfer and control groups to evaluate the associations between birth at and initial stabilisation in a hospital with a local neonatal unit and early postnatal transfer; between infants in the non-tertiary care and control groups to evaluate the associations between birth, initial stabilisation, and care in a hospital with a local neonatal unit without early postnatal transfer; and between infants in the upward transfer and non-tertiary care groups to evaluate the association between early postnatal transfer compared with continuing care in a local neonatal unit, among infants born in a local neonatal unit.

In a secondary analysis we identified matched groups of infants in horizontal transfer and control groups to evaluate the association between early postnatal transfer and initial stabilisation in a tertiary hospital (to separate postnatal transfer from initial stabilisation at a lower intensity hospital).

The study protocol was sent to all English neonatal units on 31 August 2016 and published on the National Neonatal Research Database website (www.imperial.ac.uk/neonatal-data-analysis-unit/ our-research/past-research-projects/) before data extraction (see supplementary file). We deviated from the study protocol by limiting analysis to infants born in England because of a high rate of missing data in infants born in Scotland and Wales and transferred to or from neonatal units that did not contribute data to the NNRD in the study period.

We extracted data from the NNRD on the variables gestational age, sex, multiplicity, maternal smoking, mode of delivery, use of antenatal steroids, year and month of first neonatal admission, network of first neonatal admission, birth weight $\mathrm{z}$ score, ${ }^{32}$ Apgar scores at one and five minutes after birth, and surfactant administered in the delivery room. These variables were included in the propensity analysis on which matching was based. Infants who died in the delivery room or were stillborn were excluded as these are incompletely captured in the NNRD. Infants with a diagnosis of trisomy 13,18 , or 21 or severe congenital malformations requiring early surgical intervention were excluded (see supplementary file) because they are more likely to be transferred or to receive palliative care, and these conditions are associated with adverse outcomes. Infants for whom the indication for transfer was cardiac care or surgery were excluded for the same reason. We also excluded infants with missing data on gestational age, sex, or birth weight because these variables were essential for the propensity matching and were likely to have a large impact on the outcomes. Data on infants with a birth weight $\mathrm{z}$ score greater than 4 or less than -4 were excluded as improbable. The outcomes were death before discharge from neonatal care, severe brain injury, and their combination: survival without severe brain injury. Severe brain injury was defined as grade 3 or 4 periventricular or intraventricular haemorrhage, ${ }^{33}$ porencephalic cysts, post-haemorrhagic hydrocephalus, or cystic periventricular leucomalacia on ultrasound scan; a preterm component of the UK Department of Health definition of brain injuries occurring during or soon after birth. ${ }^{34}{ }^{35}$ Infants with no recorded ultrasound scan and no diagnosis of brain injury were coded as unknown for severe brain injury and dropped from the analyses of severe brain injury. Infants with missing data on mortality were dropped from the analysis on death before discharge. Infants missing relevant data for the analysis of survival without severe brain injury were dropped from the analysis of survival without severe brain injury-for example, infants who survived but had missing data on severe brain injury.

Detailed definitions of covariates and outcomes are provided in the supplementary file. The number needed to treat (NNT) was defined as the number of infants needed to be delivered in a tertiary hospital to avoid one case of the outcome (death, severe brain injury, or death or severe brain injury).

\section{Statistical analysis}

Data were analysed with statistical software packages $\mathrm{R}$ (version 3.2.5) and IBM SPSS (version 21.0. IBM; Armonk, NY) using the potential outcomes framework. This involved forming matched within treatment groups that were well balanced on the background variables. Matching was accomplished by propensity analysis, which entailed fitting a logistic regression of the treatment assignment (a variable that indicates upward transfer, non-tertiary care, or control) as the outcome and all the available background variables as the covariates (table 1, see full list in supplementary table 1). The regression model was supplemented by adding interactions of covariates one at a time and selecting the model with superior balance. The output of this analysis is a set of propensity scores. To reduce residual confounding we then trimmed the propensities by excluding infants with extreme propensities. The three largest groups of infants (control, upward transfer, and non-tertiary care) were matched $1: 1: 1$, replicated 50 times, forming triplets of infants with one infant from each group. ${ }^{36}$ Caliper matching based on the logits of propensities was applied with the caliper width set to 0.1. Each triplet consisted of one infant from the upward transfer group, one from the nontertiary care group, and one from the control group, born in the same year and regional network. The triplets were also matched on sex, gestational week, and use of antenatal steroids, which were regarded as principal covariates. The success of the matching process is illustrated by standardised differences of the background variables across each group before and after matching. No universally accepted limits exist for how small the standardised differences should be to indicate a good match, but one study suggested no concern for standardised differences 
between -0.2 and 0.2 , and for large study samples for standardised differences between -0.1 and $0.1 .^{36}$ The supplementary file provides a detailed description of the matching process. The methods are described in the literature. ${ }^{37-40}$ Birth weight $\mathrm{z}$ scores are not defined for infants born less than 23 gestational weeks because there are no relevant UK reference values. These infants were matched separately, using birth hospital level, sex, use of antenatal steroids, and birth weight (within $30 \mathrm{~g}$ ). After we had carried out matching in the three intervention groups, we estimated the differences in outcomes using the two tailed $t$ test.

The horizontal transfer group was much smaller than the other three groups and therefore could not be incorporated into the three way matching; instead, we matched these infants separately to controls using the same principles, but by matching one infant in the horizontal transfer group to five infants from the control group. The outcomes were assessed in a similar way, using the two tailed $t$ test for estimating the differences in outcomes between the two groups.

\section{Sensitivity analyses}

We performed two further paired, matched analyses between infants in the upward transfer group and control group and between infants in the non-tertiary care group and control group. These analyses required the formation of two matched groups (rather than three in the primary analysis) and therefore facilitated the formation of larger matched groups. With these analyses we tested the robustness of the primary findings in larger groups of infants, with different distributions of background data.

To evaluate the appropriateness of the selected caliper width, we matched infants using calipers of widths $0.05,0.15$, and 0.2 in addition to 0.1 and assessed the overall balance of background variables for each width. We also evaluated the impact of matching infants only on the propensity score, without additional matching on principal background variables.

\section{Patient and public involvement}

Owing to the retrospective nature of the study utilising an existing research database, there was no direct involvement of patients or public. However, parents are informed of the inclusion of deidentified data on their infants into the NNRD and offered the opportunity to opt-out; to date no opt-out requests have been received. Parents are represented on the steering board of the Neonatal Data Analysis Unit, which oversees the NNRD. We will disseminate results through press releases, scientific meetings, social media, and directly to parents and families and professional and health policy organisations. Examples include Bliss, the UK charity for sick and preterm babies, the European Foundation for the Care of Newborn Infants, British Association of Perinatal Medicine, and the UK Maternal and Neonatal Health Policy Unit.

\section{Results}

The population consisted of 18213 extremely preterm infants. After exclusions and separately matching infants born before 23 weeks, 17577 infants were retained (fig 1). A total of 3550 (20.2\%) of the extremely preterm infants were transferred within 48 hours of birth. Early postnatal transfers increased from $18.4 \%$ in 2008 to $21.0 \%$ in $2015(\mathrm{P}=0.03)$. The proportion of infants born in hospitals with a local neonatal unit and not transferred within 48 hours declined from $21.4 \%$ in 2008 to $9.6 \%$ in $2015(\mathrm{P}<0.001)$.

\begin{tabular}{|c|c|c|c|c|c|c|}
\hline Characteristics & Controls $(n=10866)$ & $\begin{array}{l}\text { Upward transfer } \\
(n=2158)\end{array}$ & $\begin{array}{l}\text { Standardised } \\
\text { difference* }\end{array}$ & $\begin{array}{l}\text { Non-tertiary care } \\
(n=2668)\end{array}$ & $\begin{array}{l}\text { Standardised } \\
\text { differencet }\end{array}$ & $\begin{array}{l}\text { Standardised } \\
\text { difference }\end{array}$ \\
\hline Median (interquartile range) gestational weeks & $26.0(24.9-27.0)$ & $25.6(24.6-26.4)$ & -0.21 & $27.0(26.3-27.6)$ & 0.51 & -0.70 \\
\hline Mean (SD) birth weight (g) & $807(188)$ & $797(172)$ & 0.06 & $931(193)$ & 0.50 & -0.50 \\
\hline Mean (SD) birth weight z score & $-0.20(0.89)$ & $-0.03(0.82)$ & 0.22 & $0.02(0.89)$ & 0.25 & -0.05 \\
\hline Boys & $5799(53.4)$ & $1207(55.9)$ & -0.03 & $1463(54.8)$ & -0.03 & -0.02 \\
\hline Multiple birth & $2995(27.6)$ & $497(23.1)$ & -0.09 & $556(20.8)$ & -0.15 & 0.03 \\
\hline Missing & $2(0)$ & $2(0)$ & & $0(0)$ & & \\
\hline Smoking in pregnancy & $1733(19.5)$ & $418(22.1)$ & 0.08 & $503(21.7)$ & 0.04 & -0.02 \\
\hline Missing & $1998(18.4)$ & $263(12.2)$ & & $349(13.1)$ & & \\
\hline Caesarean delivery & $4028(40.1)$ & $680(32.9)$ & 0.16 & $1208(48.5)$ & 0.21 & 0.23 \\
\hline Missing & $819(7.5)$ & $93(4.3)$ & & $177(6.6)$ & & \\
\hline Surfactant during resuscitation & $9780(94.0)$ & $2035(97.3)$ & 0.08 & $2446(93.7)$ & 0.01 & 0.11 \\
\hline Missing & $466(4.3)$ & $66(3.1)$ & & $58(2.2)$ & & \\
\hline Antenatal steroids & $9897(92.4)$ & $1714(80.3)$ & -0.25 & $2255(86.5)$ & -0.12 & -0.11 \\
\hline Missing & $153(1.4)$ & $24(1.1)$ & & $60(2.2)$ & & \\
\hline Apgar score $<3$ at $1 \mathrm{~min}$ & $1847(19.5)$ & $467(23.7)$ & -0.10 & 409 (17.1) & -0.06 & 0.12 \\
\hline Missing & $1392(12.8)$ & $186(8.6)$ & & $275(10.3)$ & & \\
\hline Apgar score $<3$ at $5 \mathrm{~min}$ & $385(4.1)$ & $101(5.2)$ & -0.02 & $80(3.4)$ & -0.02 & 0.05 \\
\hline Missing & $1426(13.1)$ & $215(10.0)$ & & $331(12.4)$ & & \\
\hline \multicolumn{7}{|c|}{$\begin{array}{l}\text { Upward transfer=infants born in hospitals with local neonatal units and transferred to tertiary hospitals within } 48 \text { hours of birth; non-tertiary care=infants born in hospitals with local neonatal } \\
\text { units and not transferred within } 48 \text { hours of birth; controls=infants born in tertiary hospitals and not transferred within } 48 \text { hours of birth. } \\
\text { *Controls versus upward transfer group. } \\
\text { tControls versus non-tertiary care group. }\end{array}$} \\
\hline
\end{tabular}


Of the 17577 infants, $10866(61.8 \%)$ were in the control group, $2158(12.3 \%)$ in the upward transfer group, $2668(15.2 \%)$ in the non-tertiary care group, and $306(1.7 \%)$ in the horizontal transfer group. The remaining 1579 infants were born in hospitals with either a special care baby unit or a maternity unit and transferred to a tertiary hospital $(\mathrm{n}=757)$, transferred downward to non-tertiary hospitals $(\mathrm{n}=70)$, born and remained in hospitals with a special care baby unit ( $n=123)$, had an unknown or unusual transfer pattern (transfer from a hospital with a special care baby unit or a local neonatal unit to a hospital with a local neonatal unit, $n=259$ ), or had an unknown or unusual place of birth (home, in transit, maternity units, out of country, $n=370$ ). Table 1 shows the background characteristics and standardised differences of the control, upward transfer, and non-tertiary care groups. The median gestational age was 25.6 weeks in the upward transfer group, 26.0 weeks in the control group, and 27.0 weeks in the non-tertiary care group.

The intervention groups were matched after propensity score assignment. The matching of infants in the upward transfer, non-tertiary care, and control groups yielded 727 triplets comprised of one infant from each group (2181 infants). The quality of the match is illustrated by the distribution of background variables and the standardised differences between the matched groups (table 2). The standardised differences after matching were smaller for all background variables compared with those in the unmatched groups (standardised differences ranging from 0.00 to 0.70 in the unmatched groups and from 0.00 to 0.068 in the matched groups). Supplementary table 1 displays summaries of all background variables that were used in the propensity analysis, and the standardised differences of the matched groups; standardisation is applied to this table so that the balances for the variables would be on compatible scales. Data on severe intraventricular haemorrhage were missing for at least one infant in 22 triplets, reducing the total number of comparable triplets to 705. Excluding triplets with missing data on survival yielded 571 triplets for analysis of death before discharge and 593 triplets for analysis of survival without severe brain injury.

Table 3 shows the estimated between group differences for the comparisons of upward transfer group with controls, non-tertiary care group with controls, and upward transfer group with non-tertiary care group. Compared with controls, infants in the

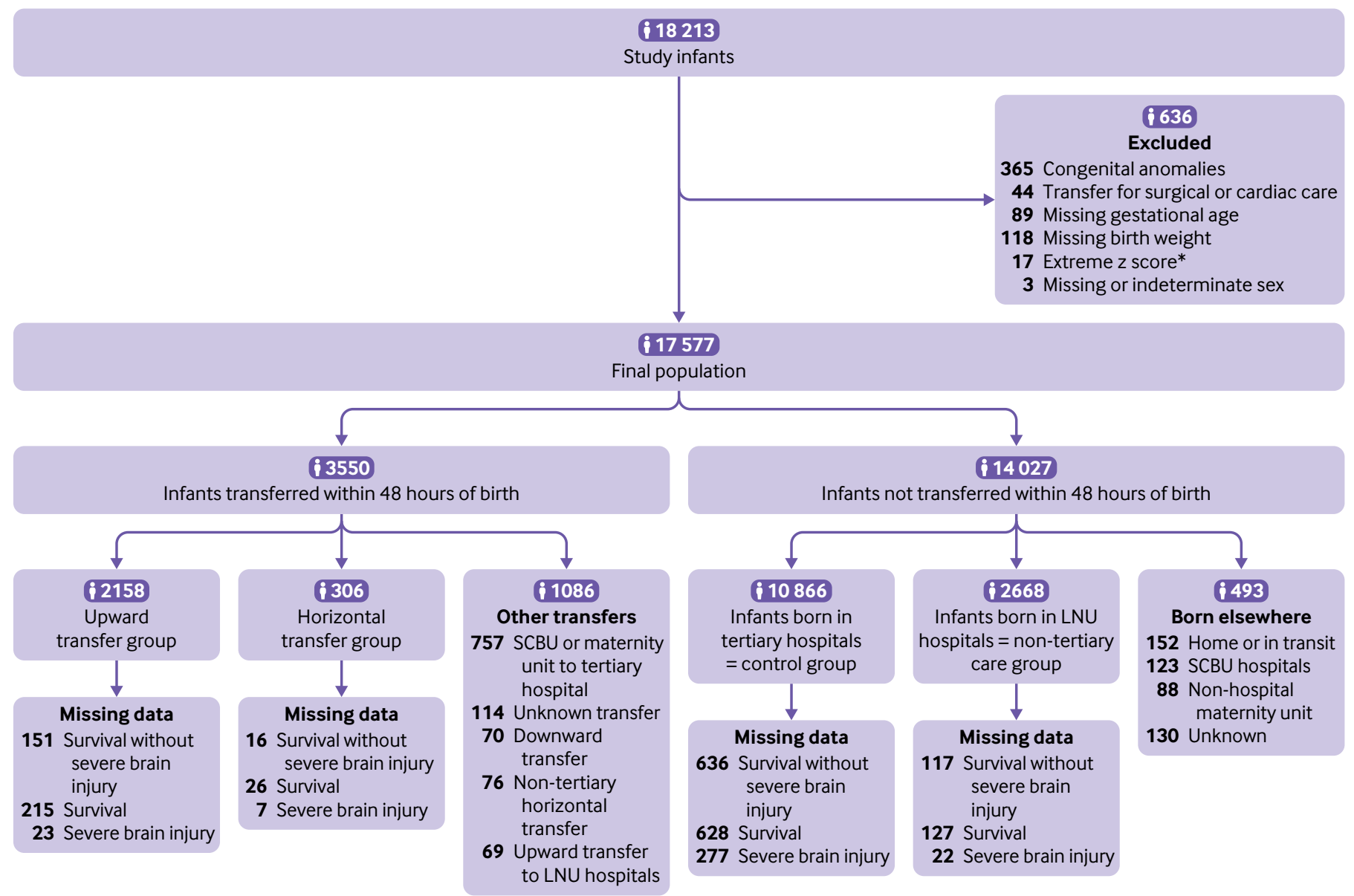

Fig 1 | Flowchart of selection process of extremely preterm infants born less than 28 gestational weeks in England between 1 January 2008 and 31 December 2015. *74 infants born at less than 23 weeks without z score were matched based on sex, birth weight, and steroid use and were included in analyses. $\mathrm{SCBU}=$ special care baby unit; $\mathrm{LNU}=$ local neonatal unit 
upward transfer group had no significant difference in the odds of death before discharge $(1.22,95 \%$ confidence interval 0.92 to 1.61 ) but significantly higher odds of severe brain injury (2.32, 1.78 to 3.06) and significantly lower odds of survival without severe brain injury $(0.60,0.47$ to 0.76$)$. The NNT to prevent one case of severe brain injury was 8 (95\% confidence interval 6 to 11) and to prevent one case of death or severe brain injury was 9 (6 to 17). Compared with controls, infants in the non-tertiary care group had significantly higher odds of death before discharge (1.34, 95\% confidence interval 1.02 to 1.77 ) but no significant difference in the odds of severe brain injury $(0.95,0.70$ to 1.30$)$ or survival without severe brain injury $(0.82,0.64$ to 1.05$)$. The NNT to prevent one case of death was 20 (95\% confidence interval 10 to 435). Compared with infants in the upward transfer group, infants in the non-tertiary care group had no significant difference in the odds of death before discharge (95\% confidence interval 1.10, 0.84 to 1.44 ) but significantly lower odds of severe brain injury $(0.41,0.31$ to 0.53$)$ and significantly higher odds of survival without severe brain injury $(1.37,1.09$ to 1.73). The NNT to prevent one case of severe brain injury was 8 (95\% confidence interval 6 to 11) and to prevent one case of death or severe brain injury was 14 (8 to 58 ).

To compare horizontal transfer and control groups, the propensity score matching was performed by matching each transferred infant to five controls, to exploit the relative abundance of infants in the control group. The groups were well matched on background variables (see supplementary table 2). This yielded 1525 matched control infants for the 305 horizontally transferred infants (table 4). Compared with controls, infants in the horizontal transfer group did not have a statistically significant difference in the odds of death before discharge $(1.09,95 \%$ confidence interval 0.80 to 1.42$)$, severe brain injury $(1.16,0.83$ to 1.54$)$, or survival without severe brain injury $(0.91,0.71$ to 1.15).

\section{Sensitivity analyses}

To independently compare early postnatal transfer with controls, and ongoing non-tertiary neonatal care with controls, we conducted matched pairwise (rather than matched triplet) analyses. These sensitivity analyses involved separately matching upward transferred infants with controls and non-tertiary care infants with controls; this approach resulted in larger matched groups for pairwise comparison. When comparing upward transfer and control groups, the propensity score matching yielded 1825 pairs of infants. After matching, infants who underwent upward transfer had no significant difference in the odds of death before discharge $(1.06,0.92$ to 1.23$)$ but significantly higher odds of severe brain injury $(1.38,1.19$ to 1.60) and significantly lower odds of survival without severe brain injury (0.84, 0.74 to 0.96 ) compared with controls (table 5). The NNT to prevent one case of severe brain injury was 18 (95\% confidence interval 12 to 33) and to prevent one case of death or severe brain injury was 24 (14 to 105). When comparing non-tertiary care with control groups, propensity score matching yielded 2519 matched pairs of infants. Infants in the non-tertiary care group had higher odds of death before discharge $(1.33,95 \%$ confidence interval 1.19 to 1.49), no significant difference in the odds of severe brain injury (1.00, 0.88 to 1.14 ), and lower odds of survival without severe brain injury (0.81, 0.73 to 0.89 ) compared with controls (table 6). The NNT to prevent one case of death was 24 (95\%

\begin{tabular}{|c|c|c|c|c|c|c|}
\hline Characteristics & $\begin{array}{l}\text { Controls } \\
(n=727)\end{array}$ & $\begin{array}{l}\text { Upward transfer } \\
(n=727)\end{array}$ & $\begin{array}{l}\text { Standardised } \\
\text { difference (matched)* }\end{array}$ & $\begin{array}{l}\text { Non-tertiary care } \\
(n=727)\end{array}$ & $\begin{array}{l}\text { Standardised } \\
\text { difference (matched) } \dagger\end{array}$ & $\begin{array}{l}\text { Standardised difference } \\
\text { (matched) } ¥\end{array}$ \\
\hline $\begin{array}{l}\text { Median (interquartile range) } \\
\text { gestational weeks }\end{array}$ & $26.0(25.0-27.0)$ & $26.0(25.0-27.0)$ & 0.000 & $26.0(25.0-27.0)$ & 0.000 & 0.000 \\
\hline Mean (SD) birth weight (g) & $900(56)$ & $900(69)$ & -0.012 & $888(65)$ & 0.015 & 0.027 \\
\hline Mean (SD) birth weight z score & $0.099(0.24)$ & $0.103(0.26)$ & -0.024 & $0.099(0.25)$ & 0.030 & 0.054 \\
\hline Boys & $298(41.0)$ & $298(41.0)$ & 0.000 & $298(41.0)$ & 0.000 & 0.000 \\
\hline Multiple birth & $158(21.7)$ & $162(22.3)$ & -0.009 & $172(23.7)$ & -0.033 & -0.024 \\
\hline Missing & 0 & 0 & & 1 & & \\
\hline Smoking in pregnancy & $129(20.1)$ & $157(24.1)$ & -0.068 & $146(23.4)$ & -0.056 & 0.012 \\
\hline Missing & $86(11.8)$ & $76(10.5)$ & & $103(14.2)$ & & \\
\hline Caesarean delivery & $416(57.2)$ & $405(55.7)$ & 0.010 & $398(54.7)$ & 0.046 & 0.036 \\
\hline Missing & 0 & 0 & & 0 & & \\
\hline Surfactant during resuscitation & $701(97.9)$ & $695(98.0)$ & -0.006 & $683(95.9)$ & 0.022 & 0.025 \\
\hline Missing & $11(1.5)$ & $18(2.5)$ & & $15(2.1)$ & & \\
\hline Antenatal steroids & $565(80.5)$ & $565(78.9)$ & 0.000 & $565(81.2)$ & 0.000 & 0.000 \\
\hline Missing & $25(3.4)$ & $11(1.5)$ & & $31(4.3)$ & & \\
\hline Apgar score $<3$ at $1 \mathrm{~min}$ & $144(21.7)$ & $144(21.8)$ & -0.014 & $139(20.9)$ & -0.016 & -0.017 \\
\hline Missing & $64(8.8)$ & $67(9.2)$ & & $62(8.5)$ & & \\
\hline Apgar score $<3$ at $5 \mathrm{~min}$ & $34(5.3)$ & $34(5.3)$ & -0.050 & $25(3.8)$ & -0.049 & 0.005 \\
\hline Missing & $84(11.6)$ & $82(11.3)$ & & $74(10.2)$ & & \\
\hline \multicolumn{7}{|c|}{$\begin{array}{l}\text { Upward transfer=infants born in hospitals with local neonatal units and transferred to tertiary hospitals within } 48 \text { hours of birth; non-tertiary care=infants born in hospitals with local neonatal } \\
\text { units and not transferred within } 48 \text { hours of birth; control=infants born in tertiary hospitals and not transferred within } 48 \text { hours of birth. } \\
\text { *Controls versus upward transfer group. }\end{array}$} \\
\hline
\end{tabular}


Table 3 | Comparison of outcomes between propensity score matched extremely preterm infants ( $<28$ gestational weeks) born in England in 2008 to 2015 , by hospital of birth and transfer status within 48 hours

\begin{tabular}{|c|c|c|c|c|c|c|c|c|c|}
\hline \multirow[b]{2}{*}{ Outcomes } & \multicolumn{3}{|c|}{ No $(\% ; 95 \% \mathrm{Cl})$} & \multicolumn{3}{|c|}{ Effect size \% $(95 \% \mathrm{Cl})$} & \multicolumn{3}{|c|}{ Odds ratio $(95 \% \mathrm{Cl}) ; \mathrm{P}$ value } \\
\hline & $\begin{array}{l}\text { Upward } \\
\text { transfer }\end{array}$ & $\begin{array}{l}\text { Non-tertiary } \\
\text { care }\end{array}$ & Controls & $\begin{array}{l}\text { Upward } \\
\text { transfer } \\
\text { v controls }\end{array}$ & $\begin{array}{l}\text { Non-tertiary } \\
\text { care v controls }\end{array}$ & $\begin{array}{l}\text { Non-tertiary care } \\
\text { v upward transfer }\end{array}$ & $\begin{array}{l}\text { Upward } \\
\text { transfer } \\
\text { v controls }\end{array}$ & $\begin{array}{l}\text { Non-tertiary } \\
\text { care v controls }\end{array}$ & $\begin{array}{l}\text { Non-tertiary } \\
\text { care } v \text { upward } \\
\text { transfer }\end{array}$ \\
\hline $\begin{array}{l}\text { Death before } \\
\text { discharge } \\
(n=571)\end{array}$ & $\begin{array}{l}140(24.5 ; \\
\text { (20.9 to } 28.1)\end{array}$ & $\begin{array}{l}150(26.3 ; \\
22.6 \text { to } 30.0)\end{array}$ & $\begin{array}{l}120(21.0 ; \\
17.6 \text { to } 24.4)\end{array}$ & $\begin{array}{l}3.50 \\
(-1.47 \text { to } 8.47)\end{array}$ & $\begin{array}{l}5.25 \\
(0.23 \text { to } 10.27)\end{array}$ & $\begin{array}{l}1.75 \\
(-3.40 \text { to } 6.90)\end{array}$ & $\begin{array}{l}1.22 \\
(0.92 \text { to } 1.61) ; \\
0.16\end{array}$ & $\begin{array}{l}1.34 \\
(1.02 \text { to } 1.77) ; \\
0.04\end{array}$ & $\begin{array}{l}1.10 \\
(0.84 \text { to } 1.44) ; \\
0.50\end{array}$ \\
\hline $\begin{array}{l}\text { Severe brain } \\
\text { injury }(n=705)\end{array}$ & $\begin{array}{l}194(27.5 ; \\
24.2 \text { to } 30.9)\end{array}$ & $\begin{array}{l}95(13.5 ; \\
10.9 \text { to } 16.1)\end{array}$ & $\begin{array}{l}99(14.0 ; \\
11.4 \text { to } 16.7)\end{array}$ & $\begin{array}{l}13.48 \\
(9.22 \text { to } 17.74)\end{array}$ & $\begin{array}{l}-0.56 \\
(-4.24 \text { to } 3.12)\end{array}$ & $\begin{array}{l}-14.04 \\
(-18.28 \text { to }-9.80)\end{array}$ & $\begin{array}{l}2.32 \\
(1.78 \text { to } 3.06) ; \\
<0.001\end{array}$ & $\begin{array}{l}0.95 \\
(0.70 \text { to } 1.30) ; \\
0.76\end{array}$ & $\begin{array}{l}0.41 \\
(0.31 \text { to } 0.53) ; \\
<0.001\end{array}$ \\
\hline $\begin{array}{l}\text { Survival without } \\
\text { severe brain injury } \\
(n=593)\end{array}$ & $\begin{array}{l}338(57.0 ; \\
42.9 \text { to } 61.1)\end{array}$ & $\begin{array}{l}382(64.4 ; \\
60.5 \text { to } 68.4)\end{array}$ & $\begin{array}{l}408(68.8 ; \\
65.0 \text { to } 72.6)\end{array}$ & $\begin{array}{l}11.80 \\
(6.21 \text { to } 17.39)\end{array}$ & $\begin{array}{l}-4.38 \\
(1.11 \text { to }-9.87)\end{array}$ & $\begin{array}{l}7.42 \\
(1.75 \text { to } 13.09)\end{array}$ & $\begin{array}{l}0.60 \\
(0.47 \text { to } 0.76) ; \\
<0.001\end{array}$ & $\begin{array}{l}0.82 \\
(0.64 \text { to } 1.05) ; \\
0.11\end{array}$ & $\begin{array}{l}1.37 \\
(1.09 \text { to } 1.73) ; \\
0.009\end{array}$ \\
\hline
\end{tabular}

Upward transfer=infants born in hospitals with local neonatal units and transferred to tertiary hospitals within 48 hours of birth; non-tertiary care=infants born in hospitals with local neonatal units and not transferred within 48 hours of birth; controls=infants born in tertiary hospitals and not transferred within 48 hours of birth.

confidence interval 15 to 57) and to prevent one case of death or severe brain injury was 24 (14 to 73).

The effect of using different caliper widths was evaluated $(0.05,0.1,0.15$, and 0.2$)$ for propensity score matching. The rates of outcomes were robust to changes in caliper width (see supplementary table 3 ). Contrary to expectations, the balance between upward transfer and non-tertiary care groups was improved with increasing caliper width, but the balance between controls and the other groups declined with increasing caliper width. The rates of outcomes changed only marginally. The caliper width of 0.1 was retained. The balance of background variables was evaluated also using only propensity scores; this did not yield a superior match compared with matching on both propensity score and principal variables and did not result in materially different rates of outcomes across the different groups (see supplementary table 4).

\section{Discussion}

By applying a robust matched analysis we found that extremely preterm infants born in a site without tertiary neonatal care had a higher risk of adverse outcomes. These results are from a high income, centrally funded, national healthcare system with high uptake of antenatal steroids and routine use of specialised neonatal transfer services. This association between non-tertiary birth and adverse outcomes is seen in both infants who underwent early postnatal transfer and infants who remained in a non-tertiary neonatal hospital.

\section{Strengths and limitations of this study}

Our study has notable strengths. We prespecified our protocol and analysis plan and focused on the objective, clinically important outcomes, death and severe brain injury. ${ }^{34}$ We used individual data from a population level dataset of more than 17000 extremely preterm infants, making this one of the largest studies to date. We applied a robust approach, using propensity score matching for multiple treatments and matching additionally on predefined principal variables to account for measured confounders. The formed groups were well balanced for distributions of covariates, and independently matched pairwise sensitivity analyses confirmed our findings. The predefined principal variables for matching were sex, gestational age, and use of antenatal steroids, all of which have a major impact on outcome. ${ }^{41}$ The final matched groups were similar for all measured background variables.

The main limitation of this study is that propensity score matching does not account for unmeasured confounders. This limitation could be dealt with by an instrumental variable approach, but we were unable to identify a suitable instrument in the available data. However, the features of propensity score matching enable reliable comparisons using observational data by eliminating the chance for errors resulting from false assumptions of the nature of background variables, and eliminating the temptation of selecting the most attractive statistical model. ${ }^{36}{ }^{42}$ We used all available pretreatment variables in the propensity score, as suggested previously. ${ }^{43}$

Through the application of careful matching we have limited the potential for measured confounders to influence the result. Nevertheless, important unmeasured factors need to be considered, including type and management of obstetric conditions, and stillbirths and delivery room deaths. In the analyses we did not match for obstetric variables such as placental disorders, presentation, and pre-eclampsia because they are not consistently recorded in the NNRD. The

\begin{tabular}{|c|c|c|c|c|c|}
\hline \multirow[b]{2}{*}{ Outcomes } & \multicolumn{2}{|c|}{ No $(\% ; 95 \% \mathrm{Cl})$} & \multirow[b]{2}{*}{ Effect size \% $(95 \% \mathrm{Cl})$} & \multirow[b]{2}{*}{ Odds ratio $(95 \% \mathrm{Cl})$} & \multirow[b]{2}{*}{ P value } \\
\hline & Horizontal transfer $(n=305)$ & Controls $(n=1525)$ & & & \\
\hline Death before discharge & $64(21.0 ; 15.4$ to 26.8$)$ & $299(19.6 ; 14.0$ to 25.4$)$ & $1.41(-4.39$ to 7.20$)$ & $1.09(0.80$ to 1.42$)$ & 0.55 \\
\hline Severe brain injury & $52(17.0 ; 12.1$ to 22.1$)$ & $230(15.1 ; 10.1$ to 20.1$)$ & $2.02(-3.04$ to 7.07$)$ & $1.16(0.83$ to 1.54$)$ & 0.36 \\
\hline Survival without severe brain injury & $199(65.2 ; 58.6$ to 71.8$)$ & $1028(67.4 ; 60.8$ to 74.0$)$ & $-2.14(-8.91$ to 4.64$)$ & $0.91(0.71$ to 1.15$)$ & 0.43 \\
\hline
\end{tabular}




\begin{tabular}{|c|c|c|c|c|c|}
\hline Outcomes & Upward transfer $(n=1825)$ & Controls $(n=1825)$ & Effect size $\%(95 \% \mathrm{Cl})$ & Odds ratio $(95 \% \mathrm{Cl})$ & $P$ value \\
\hline Death before discharge & $523(28.7 ; 26.6$ to 30.8$)$ & $500(27.4 ; 25.3$ to 29.5$)$ & $1.30(-1.68$ to 4.28$)$ & $1.06(0.92$ to 1.23$)$ & 0.38 \\
\hline Severe brain injury & $471(25.8 ; 23.9$ to 27.8$)$ & $368(20.2 ; 18.4$ to 22.0$)$ & $5.68(3.03$ to 8.31$)$ & $1.38(1.19$ to 1.60$)$ & $<0.001$ \\
\hline
\end{tabular}

type and management of obstetric factors impact on neonatal outcomes and might have influenced our results. However, because complicating obstetric conditions are associated with worse neonatal outcomes ${ }^{44}$ and are concentrated in tertiary hospitals, their exclusion from the analysis is likely to lead to an underestimate of any benefit associated with birth in a tertiary hospital. ${ }^{45} \mathrm{~A}$ further limitation of this study is the exclusion of stillborn infants and those who died in the delivery room. This was unavoidable because the NNRD is primarily designed to hold data on neonatal admissions and has incomplete data on stillbirths and delivery room deaths. Because initiation of intensive care for the most extremely preterm infants is more common in tertiary hospitals, ${ }^{46}$ the most compromised and extremely preterm infants, with the highest rates of adverse outcomes, were more likely to have survived to admission in tertiary hospitals. Therefore any bias introduced by the exclusion of deaths in the delivery room is likely to be in the opposite direction to our findings and in favour of non-tertiary hospitals. We also recognise that we were unable to identify infants who underwent in utero transfer to tertiary hospitals before delivery because these data are not systematically captured in the NNRD. This would have permitted comparison between in utero and postnatally transferred infants.

\section{Interpretation of the findings}

Our findings indicate that birth in a non-tertiary hospital and early postnatal transfer are associated with an increase in death and severe brain injury, even in the context of specialised neonatal transport services and advanced neonatal care. This suggests that approaches to reduce preterm mortality and morbidity ${ }^{47}$ should focus on ensuring, whenever possible, that extremely preterm infants are born in a setting with tertiary neonatal care. ${ }^{48}$ These data also indicate room for improvement in the current English networked model of neonatal care, as the median gestational age before matching in the upward transfer group was lower than in the control group. This indicates that many extremely preterm infants are not born in a tertiary hospital.

Extremely preterm infants contribute disproportionately to both neonatal deaths and perinatal brain injuries. ${ }^{34}$ Our study indicates that prioritising near universal delivery of extremely preterm infants in a setting with tertiary neonatal services, as found in many other high income countries, ${ }^{17} 4950$ is likely to reduce neonatal death and brain injury. ${ }^{35}$ The rate of severe brain injury was not significantly higher in non-transferred infants who remained in non-tertiary neonatal hospitals compared with controls. This finding has two possible explanations: these infants might have died before severe brain injury was detected, as mortality was higher in this group, or there may be a mechanistic link between early postnatal transfer and brain injury related to physiological instability or vibration injury during transport. ${ }^{51}$

\section{Results in the context of other studies}

Our results are in accord with previous work, including a study of 67596 very low birth weight infants born in the USA between 1997 and 2004. This study concluded that postnatal transfer within 48 hours was associated with a higher rate of intraventricular haemorrhage (all grades). ${ }^{24}$ However, the study had several limitations. Infants were identified by birth weight rather than gestational age even though decisions about antenatal transfer tend to be guided by gestational age. As a result, infants small for gestational age-recognised to have a higher prevalence of neonatal morbidities, are likely to have been overrepresented in the transfer group, potentially biasing the results. Furthermore, potential perinatal confounders, such as use of antenatal steroids were not included in the analysis, whereas postnatal diagnoses (eg, necrotising enterocolitis) were included as confounders, even though they might have

\begin{tabular}{|c|c|c|c|c|c|}
\hline \multirow[b]{2}{*}{ Outcomes } & \multicolumn{2}{|c|}{ No $(\% ; 95 \% \mathrm{Cl})$} & \multirow[b]{2}{*}{ Effect size \% $(95 \% \mathrm{Cl})$} & \multirow[b]{2}{*}{ Odds ratio $(95 \% \mathrm{Cl})$} & \multirow[b]{2}{*}{$P$ value } \\
\hline & Non-tertiary care $(n=2519)$ & Controls $(n=2519)$ & & & \\
\hline Death before discharge & $529(21.0 ; 18.5$ to 23.5$)$ & $421(16.7 ; 14.2$ to 19.2$)$ & $4.29(1.77$ to 6.81$)$ & $1.33(1.19$ to 1.49$)$ & $<0.001$ \\
\hline Severe brain injury & 327 (13.0; 10.9 to 15.2) & $328(13.0 ; 10.8$ to 15.2$)$ & $-0.03(-2.23$ to 2.18$)$ & $1.00(0.88$ to 1.14$)$ & 0.98 \\
\hline Survival without severe brain injury & $1753(69.6 ; 66.8$ to 72.5$)$ & $1864(74.0 ; 71.1$ to 76.8$)$ & $-4.32(-7.26$ to -1.37$)$ & $0.81(0.73$ to 0.89$)$ & $<0.001$ \\
\hline
\end{tabular}


occurred after the intervention (transfer) and could potentially have been related to transfer. We avoided these limitations by forming matched groups based exclusively on factors that preceded early postnatal transfer and including gestational age and use of antenatal steroids, which have a strong influence on outcome.

Our study included the comparison of infants transferred between tertiary hospitals. This analysis was aimed at separating any possible effects relating to early postnatal transfer from delivery room care and initial stabilisation at a non-tertiary hospital. Three studies attempted similar comparisons, ${ }^{52-54}$ all single centre studies with small sample sizes, and two were undertaken more than 20 years ago. We did not find a statistically significant detrimental association between horizontal transfer and outcomes, but this result should be treated with caution. Although our study included the largest described population of horizontally transferred infants, the size of this group was small, comprising only 306 infants in an eight year period.

\section{Conclusions and policy implications}

Extremely preterm birth in a non-tertiary neonatal setting is associated with a higher risk of death and lower survival without severe brain injury compared with infants born in a tertiary neonatal setting. These findings are in the context of specialised neonatal transfer services, high uptake of antenatal steroids, and the application of evidence based perinatal care. This has important policy implications for perinatal health services, indicating that care pathways that promote the birth of extremely preterm infants in hospitals with tertiary perinatal facilities should be considered a priority.

Electronic patient data recorded at participating neonatal units that collectively form the United Kingdom Neonatal Collaborative (UKNC) are transmitted to the Neonatal Data Analysis Unit (NDAU) to form the National Neonatal Research Database (NNRD). NM established and directs the NNRD. We thank the families that agreed to the inclusion of their infants' data in the NNRD, the health professionals who recorded the data, and Evgeniy Statnikov, Richard Colquhoun, and Surbhi Shah at the NDAU for statistical and administrative support.

Contributing neonatal units and clinical leads: Airedale General Hospital, Keighley; Matthew Babirecki, Arrowe Park Hospital, Upton; Anand Kamalanathan, Barnet Hospital, Barnet; Tim Wickham, Barnsley District General Hospital, Barnsley; Kavi Aucharaz, Basildon Hospital, Basildon; Aashish Gupta, Basingstoke and North Hampshire Hospital, Basingstoke; Nicola Paul, Bassetlaw District General Hospital, Worksop; Lai Men Wong, Bedford Hospital, Bedford; Anita Mittal, Birmingham City Hospital, Birmingham; Penny Broggio, Birmingham Heartlands Hospital, Birmingham; Pinki Surana, Birmingham Women's Hospital, Birmingham; Anju Singh, Bradford Royal Infirmary, Bradford; Sunita Seal, Broomfield Hospital, Chelmsford; Ahmed Hassan, Calderdale Royal Hospital, Halifax; Karin Schwarz, Chelsea and Westminster Hospital, London; Mark Thomas, Chesterfield and North Derbyshire Royal Hospital, Chesterfield; Aiwyne Foo, Colchester General Hospital, Colchester; Jo Anderson, Conquest Hospital, St Leonards-on-Sea; Graham Whincup, Countess of Chester Hospital, Chester; Stephen Brearey, Croydon University Hospital, Thorton Heath; John Chang, Cumberland Infirmary, Carlisle; Khairy Gad, Darent Valley Hospital, Dartford; Abdul Hasib, Darlington Memorial Hospital, Darlington; Mehdi Garbash, Derriford Hospital, Plymouth; Alex Allwood, Diana Princess of Wales Hospital, Grimsby; Pauline Adiotomre, Doncaster Royal Infirmary, Doncaster; Nigel Brooke, Dorset County Hospital, Dorchester; Abby Deketelaere, East Surrey Hospital,
Redhill; K Abdul Khader, Epsom General Hospital, Epsom; Ruth Shephard, Frimley Park Hospital, Camberley; Sanghavi Rekha, Furness General Hospital, Barrow-in-Furness; Belal Abuzgia, George Eliot Hospital, Nuneaton; Mukta Jain, Gloucester Royal Hospital, Gloucester; Simon Pirie, Good Hope Hospital, Sutton Coldfield; Pinki Surana, Great Western Hospital, Swindon; Stanley Zengeya, Guy's and St Thomas' Hospital, London; Timothy Watts, Harrogate District Hospital, Harrogate; Sobia Balal, Hereford County Hospital, Hereford; Cath Seagrave, Hillingdon Hospital, Uxbridge; Tristan Bate, Hinchingbrooke Hospital, Huntington; Hilary Dixon, Homerton Hospital, London; Narendra Aladangady, Hull Royal Infirmary, Hull; Hassan Gaili, Ipswich Hospital, Ipswich; Matthew James, James Cook University Hospital, Middlesborough; Mithilesh Lal, James Paget Hospital, Gorleston; Priyadarshan Ambadkar, Kettering General Hospital, Kettering; Poornima Pandey, Kings College Hospital, Camberwell; Ann Hickey, King's Mill Hospital, Sutton-in-Ashfield; Simon Rhodes, Kingston Hospital, Kingston-upon-Thames; Vinay Pai, Lancashire Women and Newborn Centre, Burnley; Meera Lama, Leeds Neonatal Service, Leeds; Lawrence Miall, Leicester General Hospital, Leicester; Jonathan Cusack, Leicester Royal Infirmary, Leicester; Venkatesh Kairamkonda, Leighton Hospital, Crewe; Michael Grosdenier, Lincoln County Hospital, Lincoln; Lakshmi Kollipara, Lister Hospital, Stevenage; Jonathan Kefas, Liverpool Women's Hospital, Liverpool; Bill Yoxall, Luton and Dunstable Hospital, Luton; Jennifer Birch, Macclesfield District General Hospital, Macclesfield; Gail Whitehead, Manor Hospital, Walsall; Raghavendra Krishnamurthy, Medway Maritime Hospital, Gillingham; Palaniappan Sashikumar, Milton Keynes General Hospital, Milton Keynes; Indranil Misra, New Cross Hospital, Wolwerhampton; Tilly Pillay, Newham General Hospital, Plaistow; Imdad Ali, Nobles Hospital, Isle of Man; Prakash Thiagarajan, Norfolk and Norwich University Hospital, Norwich; Mark Dyke, North Devon District Hospital, Barnstaple; Michael Selter, North Manchester General Hospital, Manchester; Prakash Kamath, North Middlesex University Hospital, Edmonton; Lesley Alsford, North Tyneside General Hospital (previously Wansbeck), Cramlington; Vivien Spencer, Northampton General Hospital, Northampton; Subodh Gupta, Northwick Park Hospital, Harrow; Richard Nicholl, Nottingham City Hospital, Nottingham; Steven Wardle, Nottingham University Hospital (QMC), Nottingham; Steven Wardle, Ormskirk District General Hospital, Ormskirk; Sandip Chakrabarti, Oxford University Hospitals, John Radcliffe Hospital, Oxford; Eleri Adams, Peterborough City Hospital, Peterborough; Katharine McDevitt, Pilgrim Hospital, Boston; Ajay Reddy, Pinderfields General Hospital (Pontefract General Infirmary), Pontefract; David Gibson, Poole General Hospital, Poole; Minesh Khashu, Princess Alexandra Hospital, Harlow; Chinnappa Reddy, Princess Anne Hospital, Southampton; Freya Pearson, Princess Royal Hospital, Haywards Heath; Philip Amess, Princess Royal Hospital (previously Royal Shrewsbury Hospital), Shrewsbury; Sanjeev Deshpande, Princess Royal University Hospital, Orpington; Elizabeth Sleight, Queen Alexandra Hospital, Portsmouth; Charlotte Groves, Queen Charlotte's Hospital, East Acton; Sunit Godambe, Queen Elizabeth Hospital, Gateshead; Dennis Bosman, Queen Elizabeth Hospital, King's Lynn; Glynis Rewitzky, Queen Elizabeth Hospital, Woolwich; Olutoyin Banjoko, Queen Elizabeth the Queen Mother Hospital, Margate; Niraj Kumar, Queen's Hospital, Burton on Trent; Dominic Muogbo, Queen's Hospital, Romford; Wilson Lopez, Rosie Maternity Hospital, Cambridge; Angela D’Amore, Rotherham District General Hospital, Rotherham; Shameel Mattara, Royal Albert Edward Infirmary, Wigan; Christos Zipitis, Royal Berkshire Hospital, Reading. Peter De Halpert, Royal Bolton Hospital, Bolton; Paul Settle, Royal Cornwall Hospital, Truro; Paul Munyard, Royal Derby Hospital, Derby; John McIntyre, Royal Devon and Exeter Hospital, Exeter; David Bartle, Royal Hampshire County Hospital, Winchester; Katie Pain, Royal Lancaster Infirmary, Lancaster; Joanne Fedee, Royal Oldham Hospital, Oldham; Natasha Maddock, Royal Preston Hospital, Preston; Richa Gupta, Royal Stoke University Hospital, Stoke-on-Trent; Alison Moore, Royal Surrey County Hospital, Guildford; Charles Godden, Royal Sussex County Hospital, Brighton; Philip Amess, Royal United Hospital, Bath; Stephen Jones, Royal Victoria Infirmary, Newcastle-upon-Tyne; Alan Fenton, Russells Hall Hospital, Dudley; Subramanian Mahadevan, Salisbury District Hospital, Salisbury; Nick Brown, Scarborough General Hospital, Scarborough; Kirsten Mack, Scunthorpe General Hospital, Scunthorpe; Pauline Adiotomre, South Tyneside District Hospital, South Shields; Rob Bolton, Southend Hospital, Southend; Arfa Khan, Southmead Hospital, Bristol; Paul Mannix, St George's Hospital, Tooting; Charlotte Huddy, St Helier Hospital, Carshalton; Salim Yasin, St Mary's Hospital, Isle of Wight; Sian Butterworth, St Mary's Hospital, London; Sunit Godambe, St Mary's Hospital, Manchester; Sajit Nedungadi, St Michael's Hospital, Bristol; Pamela Cairns, St Peter's Hospital, Chertsey; Peter Reynolds, St Richard's Hospital, Chichester; Nick Brennan, Stepping Hill Hospital, Stockport; 
Carrie Heal, Stoke Mandeville Hospital, Aylesbury; Sanjay Salgia, Sunderland Royal Hospital, Sunderland; Majd Abu-Harb, Tameside General Hospital, Ashton-under-Lyne; Jacqeline Birch, Taunton and Somerset Hospital, Taunton; Chris Knight, The Jessop Wing, Sheffield; Simon Clark, The Royal Free Hospital, London; Marice Theron, The Royal London Hospital - Constance Green, London; Vadivelam Murthy, Torbay Hospital, Torquay; Siba Paul, Tunbridge Wells Hospital, Pembury; Hamudi Kisat, University College Hospital, London; Giles Kendall, University Hospital Coventry, Coventry; Kate Blake, University Hospital Lewisham, Lewisham; Ozioma Obi, University Hospital of North Durham, Durham; Mehdi Garbash, University Hospital of North Tees, Stockton-on-Tees; Hari Kumar, Victoria Hospital, Blackpool; Chris Rawlingson, Warrington Hospital, Warrington; Delyth Webb, Warwick Hospital, Warwick; Sumedha Bird, Watford General Hospital, Watford; Sankara Narayanan, West Cumberland Hospital, Whitehaven; no lead, West Middlesex University Hospital, Isleworth; Elizabeth Eyre, West Suffolk Hospital, Bury St Edmunds; Ian Evans, Wexham Park Hospital, Slough; Rekha Sanghavi, Whipps Cross University Hospital, Leytonstone; Caroline Sullivan, Whiston Hospital, Prescott; Ros Garr, Whittington Hospital, London; Wynne Leith, William Harvey Hospital, Ashford; Vimal Vasu, Worcestershire Royal Hospital, Worcester; Liza Harry, Worthing Hospital, Worthing; Katia Vamvakiti, Wythenshawe Hospital, Wythenshawe; Gopi Vemuri, Yeovil District Hospital, Yeovil; Megan Eaton, York District Hospital, York; Mahmoud Samy.

Contributors: All authors contributed to the study planning. NL conducted the statistical analysis and all authors contributed to the interpretation of data. $\mathrm{KH}$ drafted the initial manuscript and NL, LL, NM, and CG reviewed the manuscript for intellectual content. All authors approved the final version of the manuscript for publication. NM, LL, and CG acted as guarantors and all authors accept full responsibility for the work and the conduct of the study. KH, CG and NL had full access to all the data in the study and take full responsibility for the integrity of the data and accuracy of the data analysis. The corresponding author attests that all listed authors meet authorship criteria and that no others meeting the criteria have been omitted.

Funding: CG was funded by the UK Medical Research Council (grant No MR/N008405/1) and KH by the Foundation of Neonatal Research of southwest Finland. The funding bodies played no role in the design and conduct of the study; collection, management, analysis, or interpretation of the data; preparation, review, or approval of the manuscript; or decision to submit the manuscript for publication. All researchers are independent from funders.

Competing interests: All authors completed the ICMJE uniform disclosure form at www.icmje.org/coi disclosure.pdf and declare: no support from any organisation for the submitted work; no financial relationships with any organisations that might have an interest in the submitted work in the previous three years; no other relationships or activities that could appear to have influenced the submitted work.

Ethical approval: This study was approved by East MidlandsLeicester South research ethics committee (16/EM/0351) and approval for inclusion of the data in this study was obtained from all English neonatal units.

Data sharing: Data are available through the National Neonatal Research Database with relevant approvals (www.imperial.ac.uk/ neonatal-data-analysis-unit/neonatal-data/utilising-the-nnrd/).

The guarantors (NM, LL, and CG) affirm that the manuscript is an honest, accurate, and transparent account of the study being reported; that no important aspects of the study have been omitted; and any discrepancies from the study as planned have been explained.

This is an Open Access article distributed in accordance with the terms of the Creative Commons Attribution (CC BY 4.0) license, which permits others to distribute, remix, adapt and build upon this work, for commercial use, provided the original work is properly cited. See: http://creativecommons.org/licenses/by/4.0/.

1 Office for National Statistics. www.ons.gov.uk/. Accessed May 19 , 2017.

2 Hamilton BE, Martin JA, Osterman MJKS, Curtin SC, Mathews TJ. Births: Final data for 2014. Natl Vital Stat Rep 2015;64:1-64.

3 Stoll BJ, Hansen NI, Bell EF, et al, Eunice Kennedy Shriver National Institute of Child Health and Human Development Neonatal Research Network. Trends in care practices, morbidity, and mortality of extremely preterm neonates, 1993-2012. JAMA 2015;314:1039-51. doi:10.1001/jama.2015.10244

4 Costeloe KL, Hennessy EM, Haider S, Stacey F, Marlow N, Draper ES. Short term outcomes after extreme preterm birth in England: comparison of two birth cohorts in 1995 and 2006 (the EPICure studies). BMJ 2012;345:e7976. doi:10.1136/bmj.e7976
5 Mukerji A, Shah V, Shah PS. Periventricular/intraventricular hemorrhage and neurodevelopmental outcomes: A meta-analysis. Pediatrics 2015;136:1132-43. doi:10.1542/peds.2015-0944

6 Serenius F, Ewald U, Faroogi A. et al, Extremely Preterm Infants in Sweden Study Group. Neurodevelopmental outcomes among extremely preterm infants 6.5 years after active perinatal care in Sweden. JAMA Pediatr 2016;170:954-63. doi:10.1001/ jamapediatrics.2016.1210

7 Lasswell SM, Barfield WD, Rochat RW, Blackmon L. Perinatal regionalization for very low-birth-weight and very preterm infants: a meta-analysis. JAMA 2010;304:992-1000. doi:10.1001/ jama.2010.1226

8 Watson SI, Arulampalam W, Petrou S, et al, Neonatal Data Analysis Unit and the NESCOP Group. The effects of designation and volume of neonatal care on mortality and morbidity outcomes of very preterm infants in England: retrospective population-based cohort study. BM Open 2014;4:e004856. doi:10.1136/bmjopen-2014-004856

9 Rautava L, Lehtonen L, Peltola M, et al, PERFECT Preterm Infant Study Group. The effect of birth in secondary- or tertiary-level hospitals in Finland on mortality in very preterm infants: a birth-register study. Pediatrics 2007;119:e257-63. doi:10.1542/peds.2006-1964

10 Phibbs CS, Baker LC, Caughey AB, Danielsen B, Schmitt SK, Phibbs $\mathrm{RH}$. Level and volume of neonatal intensive care and mortality in very-low-birth-weight infants. N Engl J Med 2007;356:2165-75. doi:10.1056/NEJMsa065029

11 Lorch SA, Baiocchi M, Ahlberg CE, Small DS. The differential impact of delivery hospital on the outcomes of premature infants. Pediatrics 2012;130:270-8. doi:10.1542/peds.2011-2820

12 American Academy of Pediatrics Committee on Fetus And Newborn. Levels of neonatal care. Pediatrics 2012;130:587-97. doi:10.1542/ peds.2012-1999

13 Ministry for Social Affairs and Health. Finland. Sosiaali- ja terveysministeriö: yhtenäiset päivystyshoidon perusteet työryhmän raportti. http://urn.fi/URN:ISBN:978-952-00-2963-0. Accessed November 23, 2018.

14 Queensland Government D of H. CSCF Neonatal Services. www. health.qld.gov.au/_data/assets/pdf_file/0023/444272/cscfneonatal.pdf. Accessed November 23, 2018.

15 Gale C, Santhakumaran S, Nagarajan S, Statnikov Y, Modi N, et al, Neonatal Data Analysis Unit and the Medicines for Neonates Investigator Group. Impact of managed clinical networks on NHS specialist neonatal services in England: population based study. BMJ 2012;344:e2105. doi:10.1136/bmi.e2105

16 Bliss. Bliss baby report 2015 - England. www.bliss.org.uk/ babyreport. Accessed July 17, 2017

17 Lui K, Abdel-Latif ME, Allgood CL, et al, New South Wales and Australian Capital Territory Neonatal Intensive Care Unit Study Group. Improved outcomes of extremely premature outborn infants: effects of strategic changes in perinatal and retrieval services. Pediatrics 2006;118:2076-83. doi:10.1542/peds.2006-1540

18 Helenius K, Helle E, Lehtonen L. Amount of antenatal care days in a context of effective regionalization of very preterm deliveries. J Pediatr 2016;169:81-6. doi:10.1016/j.jpeds.2015.10.062

19 Parturients, deliveries and births - THL. www.thl.fi/en/web/thlfien/statistics/statistics-by-topic/sexual-and-reproductive-health/ parturients-deliveries-and-births. Accessed July 17, 2017.

20 Lamont RF, Dunlop PDM, Crowley P, Levene MI, Elder MG. Comparative mortality and morbidity of infants transferred in utero or postnatally. J Perinat Med 1983;11:200-3. doi:10.1515/ ipme.1983.11.4.200

21 Kollée LA, Verloove-Vanhorick PP, Verwey RA, Brand R, Ruys JH. Maternal and neonatal transport: results of a national collaborative survey of preterm and very low birth weight infants in The Netherlands. Obstet Gynecol 1988;72:729-32.

22 Lubchenco LO, Butterfield LJ, Delaney-Black V, Goldson E, Koops $\mathrm{BL}$, Lazotte DC. Outcome of very-low-birth-weight infants: does antepartum versus neonatal referral have a better impact on mortality, morbidity, or long-term outcome?Am J Obstet Gynecol 1989;160:539-45. doi:10.1016/S0002-9378(89)800225

23 Shlossman PA, Manley JS, Sciscione AC, Colmorgen GH. An analysis of neonatal morbidity and mortality in maternal (in utero) and neonatal transports at 24-34 weeks' gestation. Am J Perinatol 1997;14:44956. doi:10.1055/s-2007-994178

24 Mohamed MA, Aly H. Transport of premature infants is associated with increased risk for intraventricular haemorrhage. Arch Dis Child Fetal Neonatal Ed 2010;95:F403-7. doi:10.1136/adc.2010.183236

25 Watson A, Saville B, Lu Z, Walsh W. It is not the ride: interhospital transport is not an independent risk factor for intraventricular hemorrhage among very low birth weight infants. I Perinatol 2013;33:366-70. doi:10.1038/jp.2012.126

26 Hauspy J, Jacquemyn Y, Van Reempts P, Buytaert P, Van Vliet J. Intrauterine versus postnatal transport of the preterm infant: a shortdistance experience. Early Hum Dev 2001;63:1-7. doi:10.1016/ S0378-3782(00)00128-6 
27 Palmer KG, Kronsberg SS, Barton BA, Hobbs CA, Hall RW, Anand $\mathrm{KJ}$. Effect of inborn versus outborn delivery on clinical outcomes in ventilated preterm neonates: secondary results from the NEOPAIN trial. J Perinatol 2005;25:270-5. doi:10.1038/sj.jp.7211239

28 McNamara PJ, Mak W, Whyte HE. Dedicated neonatal retrieval teams improve delivery room resuscitation of outborn premature infants. J Perinatol 2005;25:309-14. doi:10.1038/sj.jp.7211263

29 Battersby C, Statnikov Y, Santhakumaran S, Gray D, Modi N, Costeloe $\mathrm{K}$, et al, UK Neonatal Collaborative and Medicines for Neonates Investigator Group. The United Kingdom National Neonatal Research Database: A validation study. PLoS One 2018;13:e0201815. doi:10.1371/journal.pone.0201815

30 www.datadictionary.nhs.uk. Accessed March 18, 2019.

31 NHS Clinical Reference Group. E08/S/a. Neonatal Critical Care. SCHEDULE 2-THE SERVICES A. Service Specifications. www.england. nhs.uk/commissioning/spec-services/npc-crg/group-e/e08/. Accessed March 18, 2019

32 Cole TJ, Williams AF, Wright CM, et al, RCPCH Growth Chart Expert Group. Revised birth centiles for weight, length and head circumference in the UK-WHO growth charts. Ann Hum Biol 2011;38:7-11. doi:10.3109/03014460.2011.544139

33 Papile LA, Burstein J, Burstein R, Koffler H. Incidence and evolution of subependymal and intraventricular hemorrhage: a study of infants with birth weights less than 1,500 gm. J Pediatr 1978;92:529-34. doi:10.1016/S0022-3476(78)80282-0

34 Gale C, Statnikov Y, Jawad S, Uthaya SN, Modi N, et al, Brain Injuries expert working group. Neonatal brain injuries in England: population-based incidence derived from routinely recorded clinical data held in the National Neonatal Research Database. Arch Dis Child Fetal Neonatal Ed 2018;103:F301-6. doi:10.1136/ archdischild-2017-313707

35 Safer Maternity Care -The National Maternity Safety Strategy -Progress and Next Steps. www.nationalarchives.gov.uk/doc/opengovernment-licence/. Published 2017. Accessed May 28, 2018.

36 McCaffrey DF, Griffin BA, Almirall D, Slaughter ME, Ramchand R, Burgette LF. A tutorial on propensity score estimation for multiple treatments using generalized boosted models. Stat Med 2013;32:3388-414. doi:10.1002/sim. 5753

37 Rubin DB. Randomization analysis of experimental data: The Fisher randomization test comment. J Am Stat Assoc 1980;75:591-3. doi:10.2307/2287653

38 Imbens GW, Rubin DB. Causal Inference: For Statistics, Social, and Biomedical Sciences an Introduction. Cambridge University Press, 2015. doi:10.1017/CB09781139025751

39 Battersby C, Longford N, Mandalia S, Costeloe K, Modi N, et al, UK Neonatal Collaborative Necrotising Enterocolitis (UKNC-NEC) study group. Incidence and enteral feed antecedents of severe neonatal necrotising enterocolitis across neonatal networks in England, 2012-13: a whole-population surveillance study. Lancet Gastroenterol Hepatol 2017;2:43-51. doi:10.1016/S2468 1253(16)30117-0

40 Longford NT. Searching for causes of necrotising enterocolitis. An application of propensity matching. Stat Trans. 2018;19:87-117. doi:10.21307/stattrans-2018-006
41 Roberts D, Brown J, Medley N, Dalziel SR. Antenatal corticosteroids for accelerating fetal lung maturation for women at risk of preterm birth. Cochrane Database Syst Rev 2017;3:CD004454. doi:10.1002/14651858.CD004454.pub3

42 Stuart EA. Matching methods for causal inference: A review and a look forward. Stat Sci 2010:25:1-21 doi:10.1214/09-STS313

43 Brookhart MA, Schneeweiss S, Rothman KJ, Glynn RJ, Avorn J, Stürmer T. Variable selection for propensity score models. Am J Epidemiol 2006;163:1149-56. doi:10.1093/aje/kwj149

44 Pappas A, Kendrick DE, Shankaran S, et al, Eunice Kennedy Shriver National Institute of Child Health and Human Development Neonatal Research Network. Chorioamnionitis and early childhood outcomes among extremely low-gestational-age neonates. JAMA Pediatr 2014;168:137-47. doi:10.1001/jamapediatrics.2013.4248

45 Johansson S, Montgomery SM, Ekbom A. Preterm delivery, level of care, and infant death in sweden: a population-based study. Pediatrics 2004;113:1230-5. doi:10.1542/peds.113.5.1230

46 Marlow N, Bennett C, Draper ES, Hennessy EM, Morgan AS, Costeloe KL. Perinatal outcomes for extremely preterm babies in relation to place of birth in England: the EPICure 2 study. Arch Dis Child Fetal Neonatal Ed 2014;99:F181-8. doi:10.1136/ archdischild-2013-305555

47 New ambition to halve rate of stillbirths and infant deaths - GOV. UK. www.gov.uk/government/news/new-ambition-to-halve-rate-ofstillbirths-and-infant-deaths. Accessed April 12, 2019.

48 Gale C, Hay A, Philipp C, Khan R, Santhakumaran S, Ratnavel N. In-utero transfer is too difficult: results from a prospective study. Early Hum Dev 2012;88:147-50. doi:10.1016/j. earlhumdev.2011.07.016

49 Binder S, Hill K, Meinzen-Derr J, Greenberg JM, Narendran V. Increasing VLBW deliveries at subspecialty perinatal centers via perinatal outreach. Pediatrics 2011;127:487-93. doi:10.1542/ peds.2010-1064

50 Lehtonen L, Rautava L, Korvenranta E, Korvenranta H, Peltola M, Häkkinen U. PERFECT preterm infant study. Ann Med 2011;43(Suppl 1):S47-53. doi:10.3109/07853890.2011.586359

51 Blaxter L, Yeo M, McNally D. Neonatal head and torso vibration exposure during inter-hospital transfer. Proc Inst Mech Eng H 2017;231:99-113. doi:10.1177/0954411916680235

52 Bowman E, Doyle LW, Murton LJ, Roy RN, Kitchen WH. Increased mortality of preterm infants transferred between tertiary perinatal centres. BMJ 1988;297:1098-100. doi:10.1136/ bmj.297.6656.1098

53 Harding JE, Morton SM. Adverse effects of neonatal transport between level III centres. J Paediatr Child Health 1993;29:146-9. doi:10.1111/j.1440-1754.1993.tb00469.x

54 Longhini F, Jourdain G, Ammar F. Outcomes of preterm neonates transferred between tertiary perinatal centers. Pediatr Crit Care Med 2015:16:733-8 doi:10.1097/PCC 0000000000000482

Supplementary information: List of congenital malformations, covariates, details of matching, supporting tables, and sensitivity analyses 